The Gains from Improved Market Efficiency

Trade Before and After the Transatlantic Telegraph

Persson, Karl Gunnar; Ejrnæs, Mette

Publication date:

2006

Document version

Publisher's PDF, also known as Version of record

Citation for published version (APA):

Persson, K. G., \& Ejrnæs, M. (2006). The Gains from Improved Market Efficiency: Trade Before and After the Transatlantic Telegraph. Department of Economics, University of Copenhagen. 


\section{DISCUSSION PAPERS \\ Department of Economics \\ University of Copenhagen}

\section{6-19}

The Gains from Improved Market Efficiency:

Trade Before and After the Transatlantic Telegraph

Mette Ejrnæs, Karl Gunnar Persson

Studiestræde 6, DK-1455 Copenhagen K., Denmark

Tel. +45 35323082 - Fax +4535 323000

http://www.econ.ku.dk 


\title{
The gains from improved market efficiency: Trade before and after the transatlantic telegraph.
}

\author{
Mette Ejrnæs ${ }^{1} \&$ Karl Gunnar Persson ${ }^{2}$ \\ Department of Economics, University of Copenhagen
}

26 October 2006

\begin{abstract}
This paper looks at the gains from improved market efficiency in long-distance grain trade in the second half of the $19^{\text {th }}$ century when violations of the law of one price were reduced due to improved information transmission. Two markets, a major export centre, Chicago, and a major importer, Liverpool, are analyzed. We show that there was a law of one price equilibrium throughout the period but that markets displayed spells of demand- or supply-constrained trade when the law of one price was violated. Over time adjustments back to equilibrium, as measured by the half-life of a shock, become faster, violations of the law of one price become smaller and hence less persistent. There were also significant gains from improved market efficiency but that improvement took place after the information 'regime' shifted from pre-telegraphic communication to a regime with swift transmission of information in an era which developed a sophisticated commercial press and telegraphic communication. Improved market efficiency probably stimulated trade more than falling transport costs.
\end{abstract}

Keywords: market integration, error correction, law of one price.

JEL-classification: F1, C5, N7.

\footnotetext{
${ }^{1}$ University of Copenhagen, Department of Economics, Studiestraede 6, 1455 Copenhagen K, Denmark; email: mette.ejrnes@econ.ku.dk

${ }^{2}$ University of Copenhagen, Department of Economics, Studiestraede 6, 1455 Copenhagen K, Denmark; email: karlgunnar.persson@econ.ku.dk
} 


\section{Introduction}

One important insight from historical analysis of market integration is that long distance trade often takes place out of the (transport and transaction cost adjusted) law of one price equilibrium. ${ }^{3}$ That is, the law of one price is violated, which will affect the volume of trade relative to its equilibrium value. The major source of violations of the law of one price was unreliable and slowly travelling information over long distances. In pre telegraph times a message from Chicago to Liverpool and back would take three to four weeks, but the telegraph shortened that transmission time to a few hours. A flourishing commercial press and a reliable postal system made what used to be exclusively or privately held knowledge into publicly accessible information. With the telegraph the speed at which information travelled became dramatically shorter than the speed of transporting goods for the first time in history.

Persson (1999) and Ejrnæs and Persson (2000) showed that over the last five centuries market performance improved gradually as measured by the speed at which deviations are reversed or corrected. The half-life of shocks to the law of one price in long distance trade has declined between 1500 and 1900 from years to days. The process of improved market efficiency gained momentum in the $19^{\text {th }}$ century with faster and more reliable means of information transmission. This conclusion is controversial given the evidence that aggregate price indices adjust slowly in international comparative studies. Others argue that there has been no or little decrease in the magnitude of deviations from the law of one price over very long stretches of time (Rogoff et al 2001). In this literature results on the half-life of shocks up to a year or more are frequently reported. (Giovanini 1988). However, many of these studies rely on yearly or quarterly averaged price data which conceal the day to day adjustments and hence introduce a serious downward bias to the estimates (Taylor 2001). ${ }^{4}$ This study uses weekly observations of spot prices of one commodity, wheat, and transport costs.

Another insight from historical market integration studies is that the law of one price equilibrium is rarely obtained as a stable state. It should rather be seen as an 'attractor equilibrium', that is a state

\footnotetext{
${ }^{3}$ This paper uses the same methodology as our Discussion paper 05-02 but the data have been improved and the new results are more robust. Comments from participants at the economic history seminar at Pompeu Fabra, Barcelona, from Paul Sharp and Cormac O'Gràda are gratefully acknowledged.

${ }^{4}$ A downward bias in the estimates implies an upward bias in the estimate of the half-life of shocks.
} 
to which the price reverses after a shock to equilibrium or an ongoing reversal process. This view also relies on a different view of the tâtonnement process. It is not one in which sellers and buyers exchange trade bids and counter-bids before they reach an equilibrium price at which they trade. The tâtonnement process here is one where trade takes place, albeit on a constrained level, out of equilibrium. Either buyers chase sellers who ration the supply - a case of excess demand - or sellers chase buyers who ration their purchases - a case of excess supply, in which prices are traded down. The contemporary commercial press, from which the price and transport cost data used in this study are collected, see Appendix 1 for details, give sample evidence of trade taking place outside equilibrium. The press repeatedly reported periods of excess supply and in a sequence of trading sessions you can actually trace the tâtonnement process when sellers chase buyers eventually giving in so that prices gradually fall in subsequent trading sessions. The press and business journals recorded prices and the state of the market as 'quiet' or 'busy', 'dull' or 'lively' indicating not only the volume but also the 'mood' of trade. Occasionally the recorded price was characterized as 'nominal', indicating that it was not associated with trade at all but just repeated from the preceding session and often the volume of trade was reported as below normal, that is equilibrium, trade.

The principal new problems addressed in this paper, having first demonstrated the existence of a (transport and transaction cost adjusted) law of one price equilibrium, henceforward LOOP, is

1. to measure the costs of imperfect market integration, that is the economic costs in terms of trade forgone when LOOP is violated;

2. to document the improvements in market efficiency and to estimate the gains thereof over time focussing on two periods, one before and one after the transatlantic telegraph.

An accounting framework for measuring trade forgone in disequilibrium is developed and, by implication, we assess the gains from improved market efficiency. For reasons that will be explained in section 3, word trade is used as a synonym for contract. The trade forgone is defined as the shortfall of traded (contracted) quantities when LOOP is violated from trade in the LOOP equilibrium. The intuition of the proposed framework is simple. We first determine the traded or contracted volume in the law of one price equilibrium at a major consumer and import market, Liverpool, which is supplied by a major export market, Chicago. If the price in Liverpool rises above the law of one price equilibrium then actual transactions, i.e. the quantities contracted, will be lower than in equilibrium since demand is smaller than in equilibrium (assuming a negatively 
sloped demand curve). Quantities traded are constrained by demand. If the price in Liverpool falls below the equilibrium price then transactions will be constrained by a smaller supply than in equilibrium, given an upward sloping supply curve. The costs of disequilibrium are the losses in terms of contracts forgone, that is the sum of the difference over en extended period of trading sessions between the law of one price equilibrium and disequilibrium quantities. We do not have information on actual quantities but by specifying demand and supply elasticities we can determine an equilibrium. The forgone trade will be estimated as a proportion of the equilibrium trade. We implicitly assume that a shortfall in trade will affect production.

We analyse wheat in two major markets, exports from Chicago to Liverpool, and over two periods, one pre-telegraph period 1858-62 when grain trade was lively a decade after the repeal of the British Corn Laws, and one period, 1883-89, when trade had stabilized at a high level. The latter period had access to telegraphic transmission and a specialized commercial press. ${ }^{5}$ The price data used in this study are collected from the contemporary press, see Appendix 1. We expect a major shift in market efficiency between the periods which is linked both to the expansion of trade and traders and because the two periods were characterized by radically different information 'regimes'. You can safely assume that the efficiency of a market is linked to the access to information as long as there are no serious obstacles to entry into the trade.

The paper is organized as follows. In section 2 the nature of the law of one price equilibrium is analyzed in an error correction model. Section 3 uses a simple diagram to illustrate the concept of a market exhibiting demand and supply constraints to trade and the model is then formalized. In section 4 the costs of imperfect market integration are assessed. Section 5 concludes. The data are described in Appendix 1. ${ }^{6}$

\section{The nature of the law of one price equilibrium.}

\footnotetext{
${ }^{5}$ The telegraph linking Europe and North America began to operate in 1866. The second message cabled from US reported cotton prices. Grain exports from US were almost nil in 1866. However, the great shift in the transatlantic information regime did not arrive immediately after the introduction of the telegraph but in the mid 1870's when telegraph news were diffused by the press at a daily basis. It had been ideal to find time periods closer to the opening of the transatlantic cable. However exports of US grain almost ceased during the US Civil War and did not really pick up until the 1870's.

${ }^{6}$ The approach taken in this paper is radically different from Lew and Cater (2006) which estimate the impact of telegraph density on trade in a regression inspired by a gravity model of international trade. They find a positive and large effect of the telegraph on trade.
} 
In this section we derive the definition of the law of one price, where we explicitly take into account the presence of transport and transaction costs. Let $P^{L}$ and $P^{C}$ denote the prices in Liverpool and Chicago respectively. Furthermore, we also observe the transport cost, $P^{T c}$. All prices are measured in the same currency and units, shillings per imperial quarter.

The law of one price adjusted for transport and transaction costs (LOOP) implies the following equilibrium

$$
P^{L}=(1+\delta)\left(P^{C}+P^{T c}\right) \Leftrightarrow \frac{P^{L}}{(1+\delta)\left(P^{C}+P^{T c}\right)}=1
$$

where $\delta$ measures other, that is non-observed, transaction costs, for example commissions and insurance fees. This term can also reveal a high risk premium as well as quality differentials as revealed by price differences between the grades of wheat if they differ between the export and import markets. This term is assumed to be constant and proportional to the price in Chicago plus transport costs.

Deviations from the LOOP- equilibrium can be expressed in terms of differences in the logarithm of the prices:

$$
\ln \left(\frac{P^{L}}{(1+\delta)\left(P^{C}+P^{T c}\right)}\right)=\ln \left(P^{L}\right)-\ln \left(\left(P^{C}+P^{T c}\right)\right)-\ln (1+\delta) .
$$

On the basis of deviations from the equilibrium the error correction model can be derived.

Error correction modelling of spatial price adjustments is based on the insight that equilibrium is an attractor with varying degrees of power rather than a state in which economies rest. Strictly speaking the equilibrium price is rarely obtained and when observed it often does not last many trading sessions. Adjustments back to equilibrium take time and new stochastic shocks appear frequently. The fact that the adjustment after a shock is not instantaneous implies that markets are not in equilibrium during the adjustment process and trade will be constrained (relative to equilibrium levels) either by demand or supply.

The intuition behind the error correction model is that prices in Liverpool and Chicago will react if there is a disequilibrium. In this case the prices will adjust such that the deviation from equilibrium is decreasing. The error correction model is usually expressed in differences of log prices. Let $\Delta p_{t}^{L}=\ln P_{t}^{L}-\ln P_{t-1}^{L}$ and $\Delta p_{t}^{C}=\ln \left(P_{t}^{C}\right)-\ln \left(P_{t-1}^{C}\right)$. The error correction model in this version is given by: 


$$
\begin{aligned}
& \Delta p_{t}^{L}=\alpha^{L}\left(\ln \left(\frac{P_{t-1}^{L}}{\left(P_{t-1}^{C}+P^{T c}{ }_{t-1}\right)}\right)-\lambda\right)+\varepsilon^{L}{ }_{t} \\
& \Delta p_{t}^{C}=\alpha^{C}\left(\ln \left(\frac{P_{t-1}^{L}}{\left(P_{t-1}^{C}+P^{T C}{ }_{t-1}\right)}\right)-\lambda\right)+\varepsilon^{C}{ }_{t}
\end{aligned}
$$

where $\lambda=\ln (1+\delta) \approx \delta$ and $\varepsilon_{t}^{C}$ and $\varepsilon_{t}^{L}$ are error terms with are assumed to be normally distributed with mean zero and constant variances:

$$
\left(\begin{array}{l}
\varepsilon_{t}^{L} \\
\varepsilon_{t}^{C}
\end{array}\right) \sim N\left(\left(\begin{array}{l}
0 \\
0
\end{array}\right),\left(\begin{array}{cc}
\sigma_{L}^{2} & \sigma_{L C} \\
\sigma_{L C} & \sigma_{C}^{2}
\end{array}\right)\right) .
$$

The parameters of the model can be estimated using maximum likelihood techniques. This model is a special case of the general error correction model where the equilibrium relation is assumed known. ${ }^{7}$ The expected sign of the $\alpha^{L}$ parameter is negative and it is positive for $\alpha^{C}$.

\section{The estimation results}

The model outlined above is estimated on the basis of weekly reported wheat prices in Liverpool and Chicago (for further details about the data, see Appendix 1). Table 1 below reports the results which strongly support the expectation of improved efficiency in Chicago to Liverpool trade. There is a marked decline in the half life of shocks from 4.2 to 1.7 weeks. While most of the adjustments occurred in Chicago in the early period, Liverpool took most of the adjustment in the later period. However, adjustments were mutual which indicate the absence of 'market dominance' in both periods and the parameters have the expected signs. Results differ a little but not significantly depending on whether we use transport cost data for ships over the Great Lakes or rail all the way to New York for shipment to Liverpool. Tests for unit roots are in Appendix 2 and sensitivity analyses are reported in Appendix 3.

Table 1- Estimates from the Error correction model applied to Chicago and Liverpool trade in wheat.

\section{Chicago Chicago}

\footnotetext{
${ }^{7}$ For a detailed description of the error correction model see: Banerjee, Dolado, Galbraith and Hendry (1993)).
} 
Liverpool Liverpool

(Rail)

\begin{tabular}{lll}
\hline Period & $1857-1862$ & $1883-1889$ \\
\hline$\alpha$ (Chicago) & $0.115^{*}$ & $0.123^{*}$ \\
& $(0.053)$ & $(0.036)$ \\
$\alpha$ (Liverpool) & $-0.038^{*}$ & $-0.219^{*}$ \\
$\lambda$ & $(0.017)$ & $(0.038)$ \\
& $0.277^{*}$ & -0.008 \\
\hline Half life time of a & $(0.014)$ & $(0.013)$ \\
shock (in weeks) & & 1.7 \\
\hline$\sigma($ Chicago)*10-2 & 7.0 & 2.9 \\
$\sigma\left(\right.$ Liverpool $* 10^{-2}$ & 2.1 & 3.0 \\
\hline $\mathrm{N}$ & 184 & 297 \\
\hline
\end{tabular}

$\lambda$ is significant and positive in the first period. In fact it is much too large to indicate unobserved costs and a risk premium only. The background for the high value of $\lambda$ has also to do with the fact that the quality quoted in Chicago (Spring No 2) is an inferior quality relative to the quality quoted in the importing market (American white). In an efficient market, and if all transport and transaction costs are observable and recorded, $\lambda$ should be zero, which it to say that the equilibrium price difference between markets are due only to transport and transaction costs. This is also the result that we have obtained for the later period. However, a word of caution is necessary here. The insurance cost, around 1-2 per cent of the value of the cargo, is (probably) not included in the price and transport cost data we use, and if so, $\lambda$ should take a positive value but close to zero. The explanation for this not being the case has to do with the fact that the grade quoted in Liverpool for most of the period was for a slightly wider denomination: in terms of grades it contains Spring No 2 and inferior Spring wheat, compared to Chicago for which we quote Spring No 2 alone (see Appendix 1). That said, the $\lambda$ for the second period indicates that the market was efficient. 
Furthermore, variance in prices falls sharply for the exporting market down to the level of the importing market. ${ }^{8}$

\section{Understanding demand and supply constraints in the trans-Atlantic wheat trade.}

In the previous section we have established that prices adjust to an equilibrium determined by the transport and transaction cost corrected law of one price. In this section we analyse how demand and supply constraints can arise in the transatlantic wheat market. It is worth noting that, despite the fact that the exposition of the argument relies on the notion of disturbances to a given equilibrium, the analysis as such does allow for a market where you have shifts in supply and/or demand curves and thus the possibility of a sequence of equilibria over time. Figure 1 illustrates the general idea as stated above and applied to wheat exported from Chicago to Liverpool, two large markets which are assumed to represent US export supply and UK import demand respectively.

$\mathrm{S}$ is the supply of Chicago wheat in Liverpool and is simply the Chicago supply curve of wheat shifted upwards by an amount equal to transport and transaction costs in bringing Chicago grain to Liverpool. D is the demand for Chicago grain in Liverpool. $P^{e q}$ is the equilibrium price and $Q^{e q}$ is the quantity contracted at that price. Assume now a supply shock in the US shifting S to S'

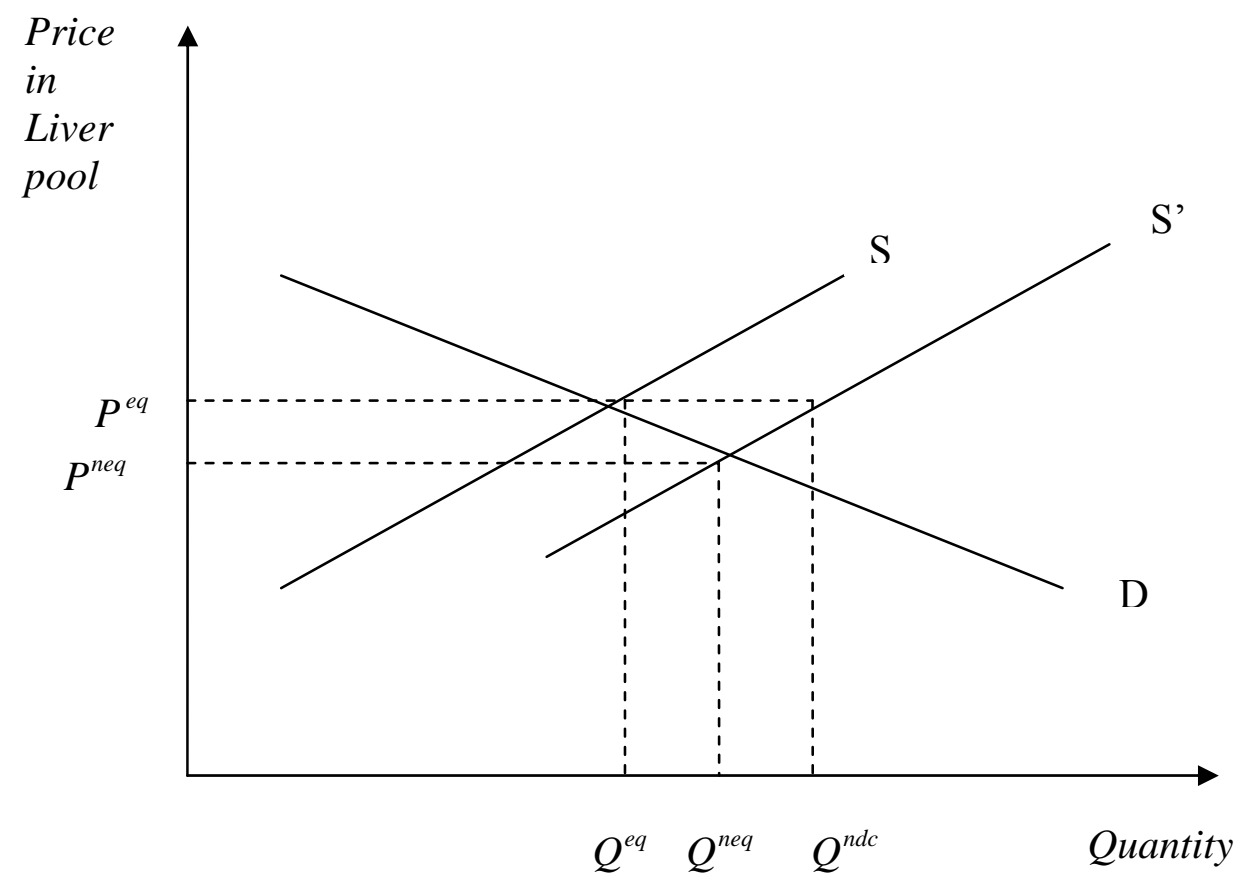

\footnotetext{
${ }^{8}$ Differences in variance in importing and exporting markets are discussed at some length in Ejrnæs, Persson and Rich 2007.
} 
Figure 1. A Shift in the Supply Curve can Generate a Transitory Period of Excess Supply

We will then have a new equilibrium quantity, $Q^{\text {neq }}$ and a new equilibrium price $P^{\text {neq }}$. The estimate of contracts forgone in disequilibrium will be made relative to the new equilibrium quantity $Q^{\text {neq }}$. However, it is plausible that the market does not adjust to the new equilibrium price instantaneously because of price rigidities, menu costs, asymmetric information etc, so let us assume that the price remains at $P^{e q}$ in the next trading session. At that price and given the new supply curve $S^{\prime}$ there will be an excess supply since traders are willing to sell $Q^{\text {ndc }}$ but contracts are bought at $Q^{e q}$. In the particular example illustrated in Figure 1 the trade forgone is the difference between $Q^{\text {neq }}$ and $Q^{e q}$.

The quantities contracted on a particular market day will not necessarily equal the imports that day or the orders to Chicago for shipments because there are speculative inventory adjustments. For example, when prices rise above equilibrium sellers might mistake that for a permanent rise and increase their imports. However, given that the actual contracts sold will be constrained by the reduced demand at an above equilibrium price, inventories will build up and reduce imports at some future date when inventory levels will be reduced. When the price in Liverpool is below the equilibrium price traders might wait until the price in Chicago falls until they place orders and in the meantime they will reduce inventories. Over an extended period of trading sessions, say, a couple of years, the contracted volumes will be (approximately) equal to the actual imports in that extended period. The reason is that the difference in the volume of inventories between the initial trading session and the final market day of the trading period will be very small relative to the sum of the contracted volumes during the entire period.

\section{A formal model of demand and supply constraints}

Let us now turn to a formal framework for calculating the loss to contracted volumes due to supply and demand constraints as described above.

We assume that the demand curve in Liverpool is given by

$$
\ln Q_{t}^{D}=\rho_{0}+\rho_{1} \ln \left(P_{t}^{L}\right)
$$

where $Q_{t}^{D}$ is the demand for American wheat in Liverpool and $P_{t}^{L}$ is the price of American wheat. $\rho_{1}$ is the price-elasticity of demand $\left(\rho_{1}<0\right)$. The supply of American wheat for the English markets is determined by the following supply function: 


$$
\ln Q_{t}^{S}=\tau_{o}+\tau_{1} \ln \left(P_{t}^{C}\right)
$$

where $Q_{t}^{S}$ is the supply of American wheat for Liverpool, $P_{t}^{C}$ is the price of American wheat in Chicago. $\tau_{1}$ is the price elasticity of supply $\left(\tau_{1}>0\right)$

In equilibrium the price in Liverpool will be equal to the price in Chicago adjusted for transaction costs

$$
P_{t}^{L}=\left(P_{t}^{C}+P_{t}^{T c}\right)(1+\delta)=P_{t}^{e q} .
$$

$P_{t}^{t c}$ is the transport cost from Chicago to Liverpool and $\delta$ measures additional transaction costs (such as port and porter charges, commissions and insurance), which are assumed to be proportional to the price in Chicago plus transport costs. The quantity obtained at the equilibrium price is denoted $\ln Q_{t}^{e q}$

$$
\ln Q_{t}^{e q}=\rho_{0}+\rho_{1} \ln \left(P_{t}^{e q}\right)=\tau_{0}+\tau_{1} \ln \left(\frac{P_{t}^{e q}}{1+\delta}-P_{t}^{T c}\right)
$$

If the price in Liverpool exceeds the transaction corrected price in Chicago $P_{t}^{L}>\left(P_{t}^{C}+P_{t}^{T c}\right)(1+\delta)$ we will observe demand constraints of wheat in Liverpool and the contracted volumes will fall. The fall is

$$
\begin{aligned}
& \ln Q_{t}^{e q}-\ln Q_{t}^{D}=\rho_{0}+\rho_{1} \ln \left(P_{t}^{e q}\right)-\left(\rho_{0}+\rho_{1} \ln \left(P_{t}^{L}\right)\right) \\
& \left.=\rho_{1}\left(\ln \left(P_{t}^{e q}\right)-\ln \left(P_{t}^{L}\right)\right)=\rho_{1}\left(\ln \left(P_{t}^{C}+P_{t}^{T c}\right)(1+\delta)\right)-\ln \left(P_{t}^{L}\right)\right)
\end{aligned}
$$

If the changes are small the left hand side of the equation above can be interpreted as the percentage fall in the contracted quantity.

On the other hand if the price in Liverpool falls below the transaction corrected price in Chicago $P_{t}^{L}<\left(P_{t}^{C}+P_{t}^{T c}\right)(1+\delta)$ we will observe supply constraints of wheat traded in Liverpool and the actual volume of contracts will fall. That fall compared to equilibrium contracting can be expressed by

$$
\begin{aligned}
& \ln Q_{t}^{e q}-\ln Q_{t}^{S}=\tau_{0}+\tau_{1} \ln \left(\frac{P_{t}^{e q}}{1+\delta}-P_{t}^{T c}\right)-\left(\tau_{0}+\tau_{1} \ln \left(\frac{P_{t}^{L}}{1+\delta}-P_{t}^{T c}\right)\right) \\
& =\tau_{1}\left(\ln \left(\frac{P_{t}^{e q}}{1+\delta}-P_{t}^{T c}\right)-\ln \left(\frac{P_{t}^{L}}{1+\delta}-P_{t}^{T c}\right)\right)=\tau_{1}\left(\ln \left(P_{t}^{C}\right)-\ln \left(\frac{P_{t}^{L}}{1+\delta}-P_{t}^{T c}\right)\right)
\end{aligned}
$$


From the two equations for the fall in quantity, the key aspect is the deviation between the prices in Liverpool and in Chicago (corrected for transaction costs). In the following section we will investigate the extent of price deviations and the implied effects on trade.

\section{Estimating the costs of imperfect market integration}

In order to estimate the cost of imperfect market integration we will need some estimates of supply and demand elasticities. What are the likely elasticities of demand and supply? There are a number of attempts to estimate UK and US elasticities of demand and supply (Irwin 1998, Williamson 1980, 1990, Olson and Harris 1959) and on that basis demand elasticity is estimated to be in the range of $0.5-1$ and US export supply elasticity to be between 0.5 and 1.5 . While there is evidence that demand for food in general is inelastic, it could be argued that US wheat is a special case since it was a prime export quality - it sold at a premium of 5 to 10 percent relative to domestic wheat in Britain and for that reason elasticities might be higher than for food or wheat in general.

Given estimates of demand and supply elasticities we can calculate the average fall in trade compared to the equilibrium. In the short run the actual import trade of US wheat might differ from the contracts sold for immediate and quasi-immediate delivery. However, as explained in section 3 imported and contracted volumes will be approximately equal over an extended period since inventory adjustments between the initial market session and the last will be small relative to the traded and imported volumes. For that reason we will henceforward use the word 'trade' as synonymous with 'contracted volume'. The average forgone trade is calculated as:

$$
\begin{aligned}
& \text { Average foregone trade }=\frac{1}{N}\left[\sum_{t \in\{\text { demand con. }\}}\left(\ln Q_{t}^{e q}-\ln Q_{t}^{D}\right)+\sum_{t \in\{\text { supply con. }\}}\left(\ln Q_{t}^{e q}-\ln Q_{t}^{S}\right)\right] \\
& =\frac{1}{N}\left[\rho_{1} \sum_{t \in\{\text { demand con. }\}}\left(\ln \left(\left(P_{t}^{C}+P_{t}^{T c}\right)(1+\delta)\right)-\ln \left(P_{t}^{L}\right)\right)+\tau_{1} \sum_{t \in\{\text { supply con. }\}}\left(\ln \left(P_{t}^{C}\right)-\ln \left(\frac{P_{t}^{L}}{1+\delta}-P_{t}^{T c}\right)\right]\right. \\
& =\frac{n^{d c} m p d^{d c}}{N}+\frac{n^{s c} m p d^{s c}}{N}
\end{aligned}
$$

where $n^{d c}$ and $n^{s c}$ are the number of trading sessions with demand constraints and supply constraints respectively and $m p d^{d c}$ and $m p d^{s c}$ are the mean price deviations when demand and 
supply constrains. ${ }^{9}$ We display the estimates of the average loss in trade in Table 2 for two pairs of values of the elasticities.

Table 2 - Estimating the forgone trade due to imperfect market integration.

\begin{tabular}{lll}
\hline & $\begin{array}{l}\text { Chicago } \\
\text { Liverpool } \\
\text { (rail) }\end{array}$ & $\begin{array}{l}\text { Chicago } \\
\text { Liverpool }\end{array}$ \\
\hline Period & $1857-1862$ & $1883-1889$ \\
\hline$\delta$ & $0.331^{*}$ & -0.008 \\
& $(0.089)$ & $(0.043)$ \\
$\mathrm{N}$ & 189 & 304 \\
\hline Demand constraint & & \\
$n^{d c}$ & 94 & 159 \\
Mean price dev. & 0.076 & 0.036 \\
Supply constraint & & \\
$n^{s c}$ & 95 & 145 \\
Mean price dev & -0.076 & -0.039 \\
\hline Mean fall in & & 5.4 \\
quantity $(\%)$ & 14.8 & \\
$\left(\rho_{1}=-1, \tau_{1}=1.5\right)$ & & \\
Mean fall in & 5.7 & \\
quantity $(\%)$ & & \\
$\left(\rho_{1}=-0.5, \tau_{1}=0.5\right)$ & & \\
\hline
\end{tabular}

Table 2 provides an upper and lower bound estimate of the trade forgone due to deviations from LOOP trade. The inefficiency of the pre-telegraph transatlantic trade is apparent. It reduces equilibrium trade by as much as 15 per cent in the upper-bound estimate and close to six per cent in

\footnotetext{
${ }^{9}$ The mean price deviations are defined as $m p d^{d c}=\frac{1}{n^{d c}} \sum_{t \in t \text { temand con } ;}\left(\ln \left(\left(P_{t}^{c}+P_{t}^{T c}\right)(1+\delta)\right)-\ln \left(P_{t}^{L}\right)\right)$ and $m p d^{s c}=\frac{1}{n^{s c}} \sum_{t \in\{\text { supply con. }\}}\left(\ln \left(P_{t}^{C}\right)-\ln \left(\frac{P_{t}^{L}}{1+\delta}-P_{t}^{T c}\right)\right.$
} 
the lower bound estimate. The gain from improved market efficiency is the difference in the mean fall in traded quantity between periods compared. First conclusion is that the gains from increased market efficiency between the first and second periods are substantial in the upper bound estimate and clearly non-trivial in the lower bound estimate. In the upper-bound estimate the gain is 9.4 per cent of equilibrium trade $(14.8-5.4=9.4)$ and in the lower bound estimate it is 3.6 per cent, that is the difference between the mean fall in quantity relative to equilibrium trade in the first period (5.7) and in the second period (2.1).

Improvement in market efficiency matters!

\section{A counterfactual}

One way of assessing the importance of the gains in trade from the improved market efficiency is to design a counter-factual scenario. The actual trade is the observed value of yearly wheat exports from USA between 1875 and 1914 measured in current US dollars. The year 1875 is chosen as the starting year of the modern information regime permitting a fairly efficient spatial arbitrage. Export of grain in the 1875 to 1914 period is considered to represent trade at the market efficiency characteristics reported in Table 2 for the 1883-89 period. Imagine now that no improvement in market efficiency took place after the 1858-62 period, which would be a likely scenario had not the transatlantic telegraph been introduced. Then trade would have been smaller than the actual trade since there were significant improvements in market efficiency between the first and second period documented in Table 2. Had market efficiency remained at the 1858-62 level we can calculate counterfactual trade to be 3.6 per cent lower than actual trade each year in the 1875-1914 period in the lower-bound estimate and to be 9.4 percent lower per year in the upper-bound estimate. The gain from improved market efficiency is the difference between trade at the 1883-89 efficiency level, which is assumed to be the efficiency level of the entire 1875-1914 period in this counterfactual estimate, and the efficiency level of the 1858-62 period. The counter-factual question then is: what will the accumulated gains from improved market efficiency be like? In Figure 2 below we present the upper-bound and lower-bound estimates. The argument is made under the assumption that from the nature of the Chicago to Liverpool trade it is possible to generalise to US wheat exports in general, but given that the UK was the major market and London and Liverpool the dominating markets in Britain, that assumption is not unreasonable. 


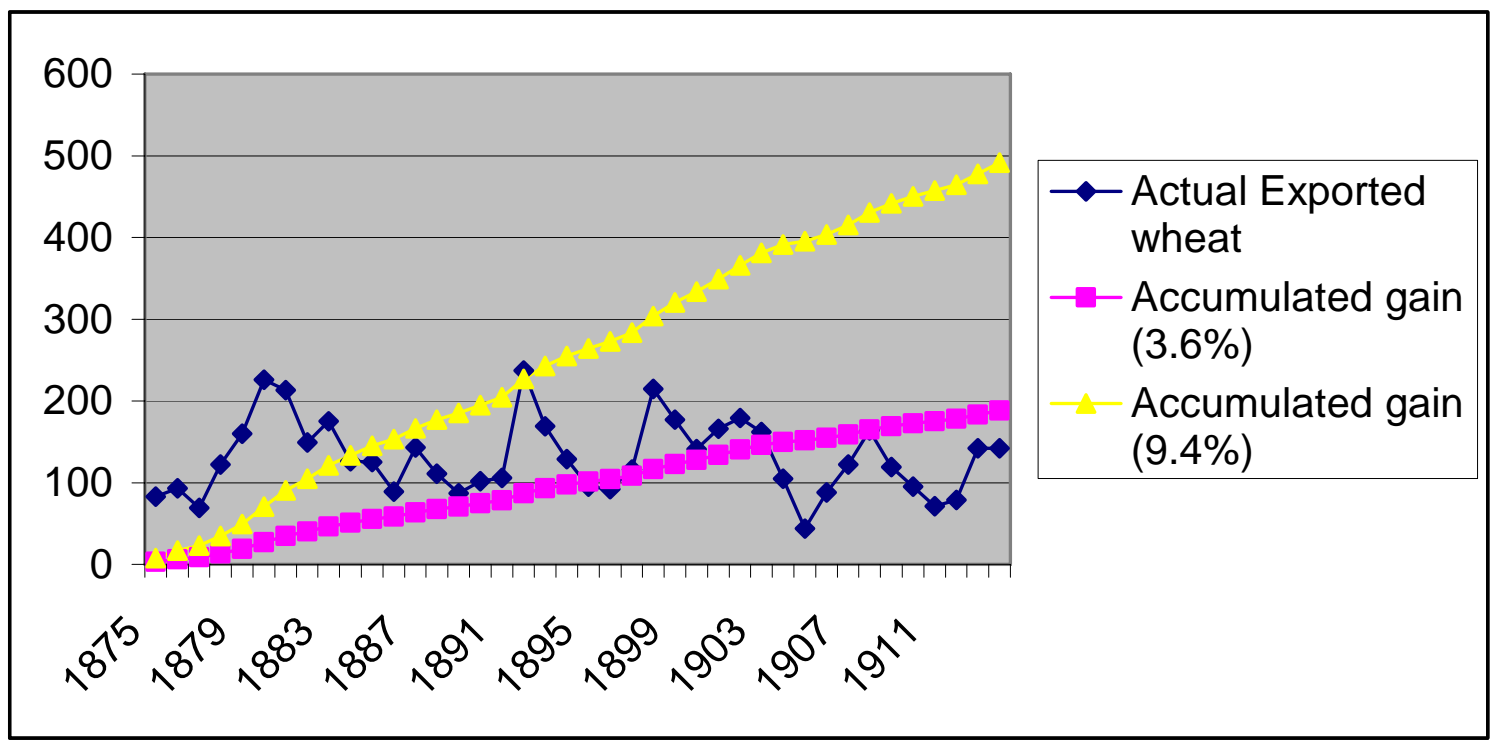

Figure 2. Actual US Wheat Exports and Accumulated Gains from Improved Market Efficiency, 1875-1914 in a Lower-Bound and Upper-Bound Estimate of Market Efficiency Gains (Millions of US dollars).

Source: Mitchell, B.R., International Historical Statistics, The Americas 1750-1988, New York: Stockton Press, 1993, Table E 3 .

Figure 2 indicates that the accumulated gains from improved market efficiency in the upper bound estimates is equivalent to about four and a half years of average wheat exports in the period or to one and a half years of average exports using the lower bound estimate. Is that gain big or small?

One way of addressing that question is to look for a standard. In the conventional view transatlantic trade flourished in the second half of the $19^{\text {th }}$ century mainly because of falling international freight rates (O'Rourke and Williamson 1999). It makes sense therefore to assess the impact of market efficiency gains compared to the gains in trade attributed to falling transport costs. In this context the relevant way to approach transport costs is to calculate so-called freight factors, i.e. freight rates as a proportion of commodity prices, e.g. the cost of shipping a bushel of wheat as a proportion of the wheat price. Calculating freight factors is appropriate when the focus is on the trade-inhibiting bias of transport costs, similar to an estimate of tariffs in ad valorem terms. If freight charges fall the gains will be distributed between consumers and producers. Producers might catch part of the gains by increasing commodity prices and consumers might enjoy falling prices. If prices increase in the producing areas - relative to what prices would be like in the absence of falling transport 
costs - export supply will be stimulated meeting the increased import demand due to falling prices in Europe. We want to know by how much. Recent estimates of the fall in the transatlantic freight factor for wheat shows that it fell by approximately 3.5 percentage points between 1850 and 1900, from ca. 10.5 to 7 percent. (Persson 2004) Almost all of that decline took place between 1875-1895. Imagine a case in which the falling transport costs were equally divided between producers and consumers. Producers would then enjoy prices about 1.75 percent higher by the end of the $19^{\text {th }}$ century because of falling transport costs relative to a situation without transport costs reductions. Let us assume, for simplicity, that the entire fall in transport costs took place in one year, in 1875. The producers would then enjoy higher prices throughout the 1875-1914 period, compared to a case without transport cost reductions. However, even with a price elasticity of supply at unity the effect of transport costs reductions would account for only 1.75 per cent higher exports, which is about half the effect in the lower bound estimate of gains from improved market efficiency.

\section{Conclusion.}

This paper brings a number of novel insights.

The LOOP is alive and kicking in the nineteenth-century international economy. Adjustment speed as measured by the half life of shocks to LOOP was not a matter of years or months but weeks, and it fell over time. That result underlines the need for high frequency data in historical PPP-studies. A method by which the costs of disequilibrium trade and, by implication, the gains from improved market efficiency can be measured has been developed. Gains are substantial in an upper bound estimate and significant in a lower bound estimate.

Market efficiency increases over time but there seems to be a regime shift caused by changes in the information technology associated with the telegraph and the development of the business press.

But are these gains big or small? It depends on the standard used. The impact of improvements in market efficiency compares well and even outpaces falling transport costs, which is the factor normally ascribed a leading role in $19^{\text {th }}$ century trade expansion. 


\section{Appendix 1: Description of the data.}

Prices refer to spot transactions on the first market day every week, usually Monday, (Tuesdays in Liverpool) and have been converted to shillings per imperial quarter.

Period 1858-62: Prices of Spring No.2 in Chicago is from Trade and Commerce of Chicago, Chicago Board of Trade Annual report, and refers to Spring No.2 except January to June 121858 when unspecified Spring. The new grading system is introduced in 1858. Prices in Liverpool from Liverpool Journal and Liverpool Courier and refer to American white. Transport costs between Chicago and New York from Chicago Board of Trade, Annual report. Transport costs between New York and Liverpool from New York Times.

Period 1883-89: Transport costs and prices in Chicago and Liverpool from the Annual Report of Chicago Board of Trade, Prices refer to Spring no. 2 in Chicago and Fair to Good Spring Wheat (US) in Liverpool from 1883 to 1886 and from 1887 Spring no.2.

Exchange rates from J. Schneider et al (eds) Währungen der Welt I, Europäische und Nordamerikanische Devisenkurse, 1777-1914, Vol 1,Stuttgart:Franz Steiner Verlag, 1991. The prices are shown in Figure A1 and A2.

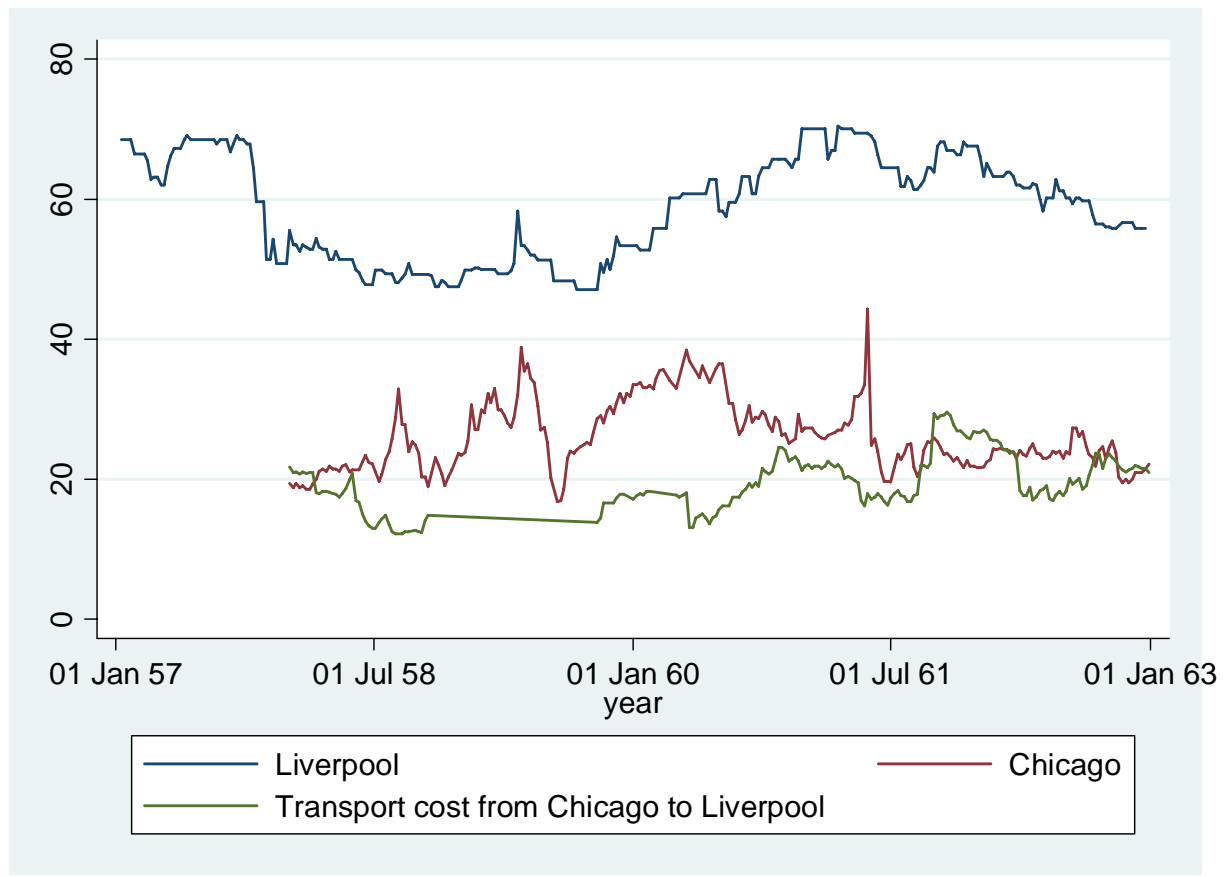

Figure A1 - The Weekly Wheat Prices in Liverpool and Chicago 1857-1862 (shillings per imperial quarter) 


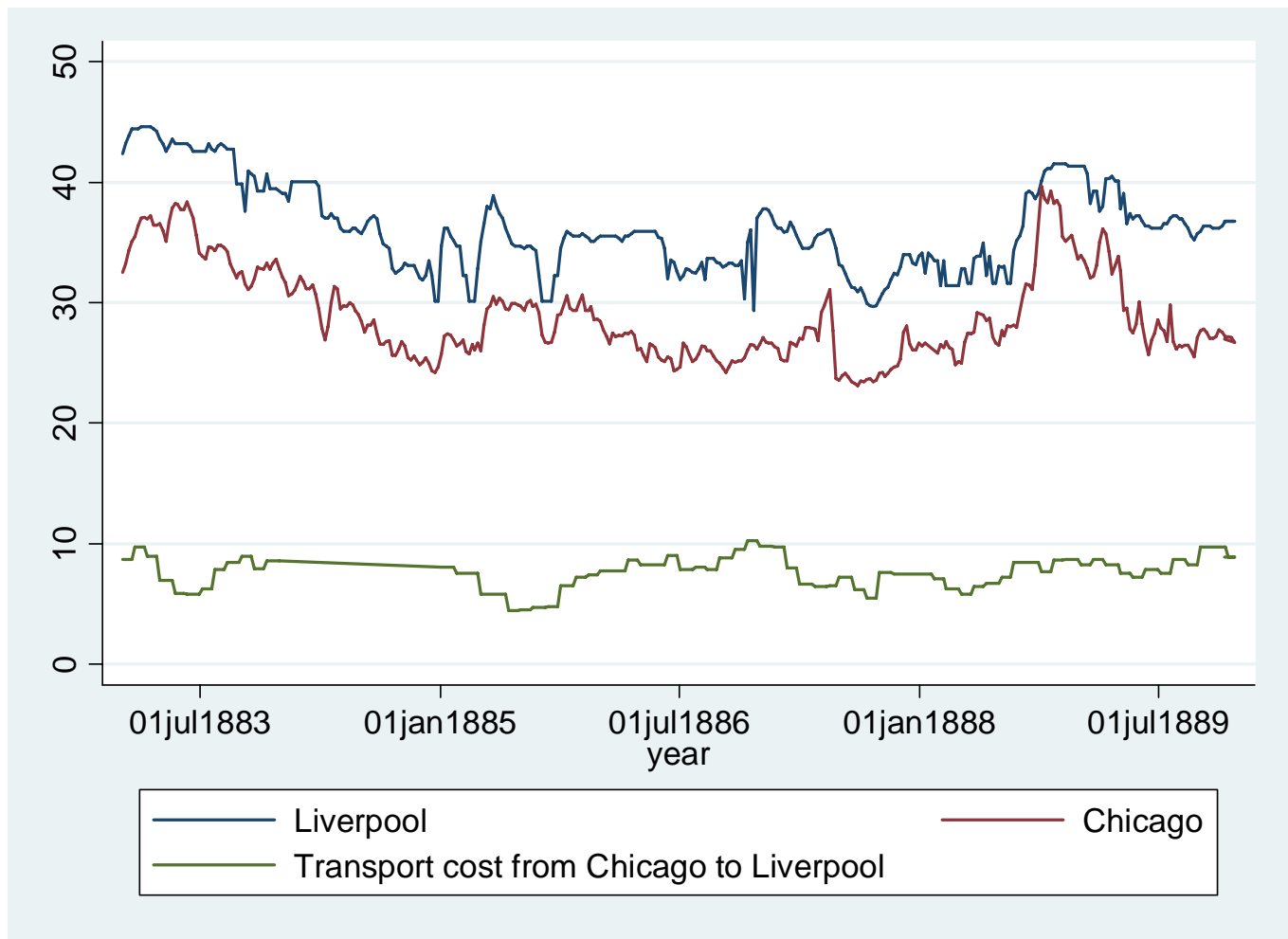

Figure A2 - The Weekly Wheat Prices in Liverpool and Chicago 1883-1889 (sShillings per imperial quarter)

\section{Appendix 2: Test for unit root}

Estimation of the error correction model relies on the assumption that the time series $\Delta \ln P_{t}^{L}, \Delta \ln P_{t}^{C}$ and $\ln \left(P_{t}^{L}\right)-\ln \left(P_{t}^{C}+P_{t}^{T c}\right)$ are stationary processes. To examine if this is the case the Dickey-Fuller test for a unit root (non-stationarity) is performed. In the Table below the results of the test are reported.

Table A1: Dickey-Fuller test for unit root

\begin{tabular}{llllll} 
Period & Time Series & test-statistic & $\begin{array}{l}\text { Critical value } \\
(5 \% \text { level })\end{array}$ & N & $\begin{array}{l}\text { Stationary/ } \\
\text { Non-stationary }\end{array}$ \\
\hline $1857-1862$ & Liverpool & -9.10 & -1.95 & 306 & Stationary \\
& Chicago & -16.09 & -1.95 & 233 & Stationary \\
& Equilibrium & -3.52 & -2.87. & 176 & Stationary \\
\hline $1883-1889$ & Liverpool & -22.70 & -1.95 & 363 & Stationary \\
& Chicago & -15.83 & -1.95 & 341 & Stationary \\
& Equilibrium & -7.59 & -2.87 & 295 & Stationary \\
\hline
\end{tabular}




\section{Appendix 3: Sensitivity analyses}

The price data for Chicago has one extreme observation, May 13, 1861. We have performed the analyses with and without this observation. Furthermore we also have used transportation cost based on rail freight rates to New York as well as the Great Lakes plus canal to New York.. Table A2 - Estimation results from the error correction model.

\begin{tabular}{|c|c|c|c|c|}
\hline & $\begin{array}{l}\text { Chicago } \\
\text { Liverpool }\end{array}$ & $\begin{array}{l}\text { Chicago } \\
\text { Liverpool } \\
\text { (Rail) }\end{array}$ & $\begin{array}{l}\text { ChicagoI } \\
\text { Liverpool }\end{array}$ & $\begin{array}{l}\text { Chicago I } \\
\text { Liverpool } \\
\text { (Rail) }\end{array}$ \\
\hline Period & $1857-1862$ & $1857-1862$ & $1857-1862$ & $1857-1862$ \\
\hline$\alpha$ (Chicago) & $\begin{array}{l}0.131 \\
(0.077)\end{array}$ & $\begin{array}{l}0.115 * \\
(0.053)\end{array}$ & $\begin{array}{l}0.038 \\
(0.054)\end{array}$ & $\begin{array}{l}0.058 \\
(0.039)\end{array}$ \\
\hline$\alpha$ (Liverpool) & $\begin{array}{l}-0.035 \\
(0.021)\end{array}$ & $\begin{array}{l}-0.038^{*} \\
(0.017)\end{array}$ & $\begin{array}{l}-0.037 \\
(0.021)\end{array}$ & $\begin{array}{l}-0.038^{*} \\
(0.018)\end{array}$ \\
\hline$\lambda$ & $\begin{array}{l}0.427 * \\
(0.019)\end{array}$ & $\begin{array}{l}0.277 * \\
(0.014)\end{array}$ & $\begin{array}{l}0.415 * \\
(0.019)\end{array}$ & $\begin{array}{l}0.269 * \\
(0.015)\end{array}$ \\
\hline $\begin{array}{l}\text { Half life time of a } \\
\text { shock (in weeks) }\end{array}$ & 3.8 & 4.2 & 8.9 & 6.9 \\
\hline$\sigma($ Chicago $) * 10^{-2}$ & 8.8 & 7.0 & 6.3 & 5.2 \\
\hline$\sigma($ Liverpool $) * 10^{-2}$ & 2.2 & 2.1 & 2.2 & 2.1 \\
\hline $\mathrm{N}$ & 109 & 184 & 109 & 182 \\
\hline
\end{tabular}

Both adjustment speed and variance are affected by the extreme observation but in opposite directions, which means that our estimate of the trade forgone by inefficient markets, which depends on adjustment speed and variance, is only marginally affected, as is revealed by Table A3. Table A3 - Estimating the forgone trade due to imperfect market integration.

$\begin{array}{llll}\text { Chicago } & \text { Chicago } & \text { Chicago } \mathrm{I} & \text { Chicago } \mathrm{I} \\ \text { Liverpool } & \text { Liverpool } & \text { Liverpool } & \text { Liverpool } \\ & \text { (rail) } & & \text { (rail) }\end{array}$




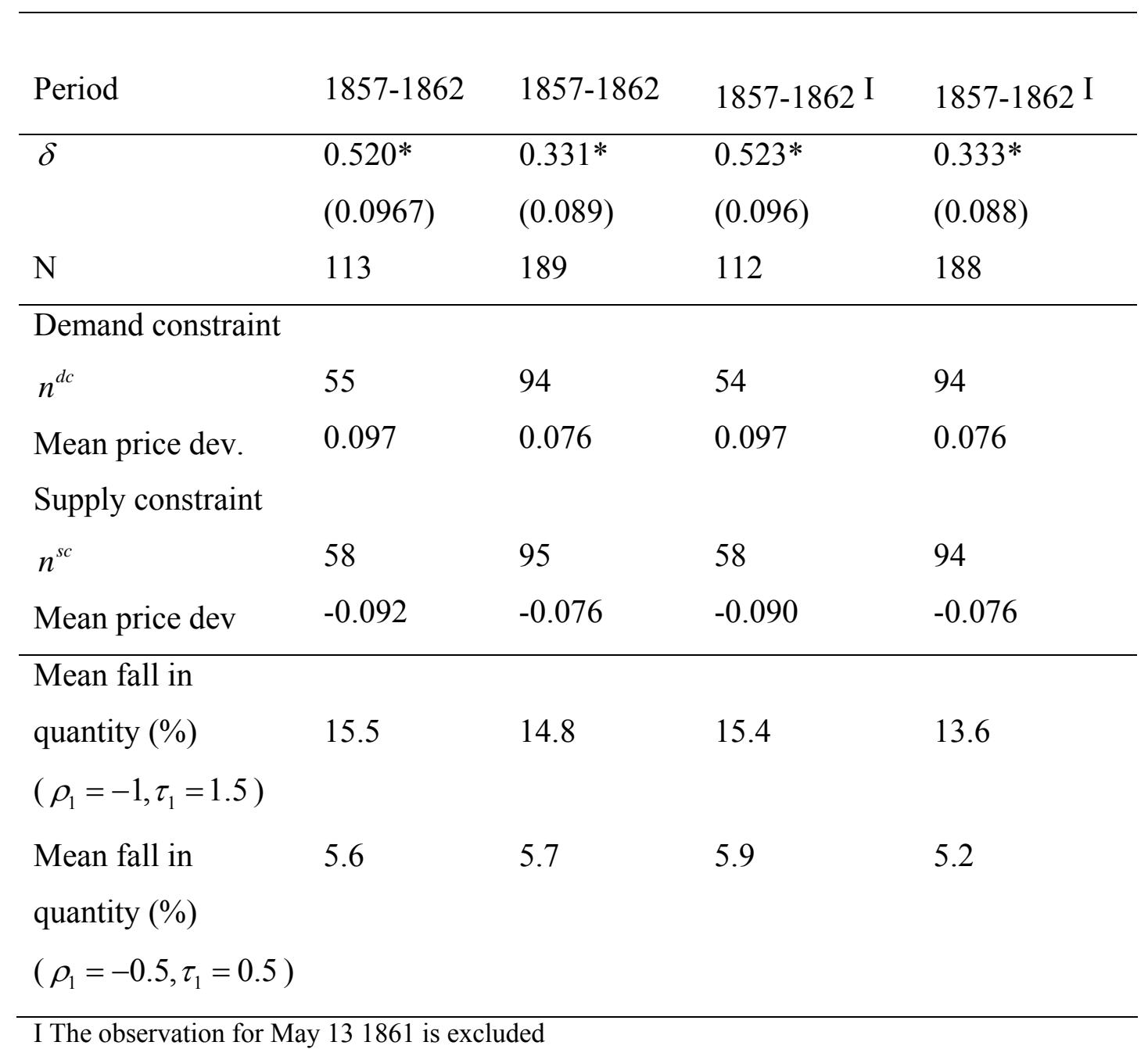




\section{References}

Banerjee, Anindya, Juan Dolado, John W. Galbraith and David F. Hendry. 1993. Cointegration, Error-correction, and the Econometric analysis of Non-stationary data, Oxford: Oxford University Press

Ejrnæs, Mette and Karl G. Persson. 2000. "Market Integration and Transport Costs in France 1825-1903: A Threshold Error Correction Approach to the Law of One Price." Explorations in Economic History, 37: 149-73.

Ejrnæs, Mette , Karl G. Persson and Søren Rich. Forthcoming. "Feeding the British: Convergence and Market Integration in $19^{\text {th }}$ Century Grain Trade." Economic History Review.

Giovannini, Alberto. 1988 “Exchange Rates and Traded Goods Prices.” Journal of International Economics, 24: 45-68.

Irwin, Douglas A. 1998. "Welfare effects of British Free Trade: Debate and Evidence from the 1840s.” Journal of Political Economy, 96(6): 1142-64.

Lew, Byron and Bruce Cater. 2006."The telegraph, co-ordination of tramp shipping, and growth in world trade 1870-1910." European Review of Economic History, 10(2):147-73.

Olson Jr., Mancur and Curtis C. Harris, Jr. 1959. "Free Trade in “Corn”: A Statistical Study of the Prices and Production of Wheat in Great Britain from 1873 to 1914." Quarterly Journal of Economics, 73:145-168.

O’Rourke, Kevin H. and Jeffrey G. Williamson. 1999. Globalization and History, The Evolution of the Nineteenth-Century Atlantic Economy, Cambridge, Mass.: MIT Press.

Persson, Karl G. 1999. Grain Markets in Europe 1500-1900, Integration and Deregulation, Cambridge: Cambridge University Press.

Persson, Karl G. 2004. “'Mind the Gap!' Transport Costs and Price Convergence in the $19^{\text {th }}$ Century Atlantic Economy." European Review of Economic History, 8 (2).

Rogoff, Kenneth, Kenneth A. Froot, and Michael Kim. 2000. "The Law of One Price over 700 years." IMF Working Paper, WP/01/174.

Taylor, Alan M. 2001. "Potential Pitfalls for the Purchasing - Power - Parity Puzzle? Sampling and Specification Biases in Mean-Reversion Tests of the Law of One Price.” Econometrica, 69: 473-98.

Williamson, Jeffrey G. 1980. “Greasing the Wheels of Sputtering Export Engines: Midwestern Grains and American Growth.” Explorations in Economic History, 17: 189-217. 
Williamson, Jeffrey G. 1990. "The Impact of the Corn Laws just Prior to Repeal.” Explorations in Economic History, 27: 123-56. 